\title{
Lateral spinal radiographs help create an accurate Risser sign grading Tomasz Kotwicki
}

\author{
Address: Department of Paediatric Orthopaedics and Traumatology, University of Medical Sciences, Poznan, Poland \\ from $5^{\text {th }}$ International Conference on Conservative Management of Spinal Deformities \\ Athens, Greece. 3-5 April 2008 \\ Published: 15 January 2009 \\ Scoliosis 2009, 4(SuppI I):OII doi:I0.II86/I748-7|6I-4-SI-OII
}

This abstract is available from: http://www.scoliosisjournal.com/content/4/SI/OI I

(c) 2009 Kotwicki; licensee BioMed Central Ltd.

\section{Background}

The Risser sign quantifies the ossification of the iliac crest in order to assess the remaining spinal growth. The clinical value of the Risser sign has been questioned for its inaccuracy. Estimation of the Risser sign based on the lateral spinal radiograph has not been reported.

\section{Purpose}

To evaluate the relevance of the lateral spinal radiograph as a tool for a more accurate Risser sign grading.

\section{Methods}

Cross sectional analysis of spinal frontal and lateral radiographs of 201 girls with idiopathic scoliosis, aged $14.6 \pm$ 2.2 years. The ossification of the posterior part of the iliac apophysis was quantified on the lateral spinal view at four grades: absent (A), partial (B), complete (C) or fused (D). The position of the posterior superior iliac spine was studied on both views as well as in pelvic specimens.

\section{Results}

The posterior one-third portion of the iliac apophysis, sagittally oriented and obscured by the sacroiliac junction, could be studied on the lateral radiograph. This revealed a modified quantification of the apophysis excursion in 58 of 201 (29\%) patients. To compare the frontal view, both advanced and/or delayed ossification were assessed with the Lateral Modifiers. Twenty-five percent of the patients at Risser 0,1 or 2 demonstrated simultaneous ossification of both anterior and posterior parts of the iliac crest.

\section{Conclusion}

1. Currently used Risser sign grading does not consider the actual excursion of the iliac apophysis. Because the apophysis is posterior and medial to the sacroiliac junction, it is not observed.
2. Iliac apophysis excursion can be accurately estimated, when the lateral spinal radiograph is analyzed and Lateral Modifiers A through D are considered.

\section{References}

I. Burwell RG, Cole AA, Cook TA, Grivas TB, Kiel AW, Moulton A, Thirwall AS, Upadhay SS, Webb JK, Wemyss-Holden SA, Whitwell DJ, Wojcik AS, Wythers DJ: Pathogenesis of idiopathic scoliosis. The Nottingham concept. Acta Orthop Belg I992, 58(Suppl I):33-58.

2. Kerr AM, Kirtley SJ, Hillman SJ, Linden ML van der, Hazlewood ME, Robb JE: The mid-point of passive hip rotation range is an indicator of hip rotation in gait in cerebral palsy. Gait Posture 2003, | 7:88-91.

3. Kotwicki T, Walczak A, Szulc A: Trunk rotation and hip joint range of rotation in adolescent girls with idiopathic scoliosis: does "the dinner plate" turns asymmetrically? Scoliosis 2008, 3:I. 